\title{
PERAN DINAS PERHUBUNGAN DALAM TATA KELOLA ANGKUTAN UMUM PERKOTAAN DI KOTA SUKABUMI
}

\author{
Asri Rahmawati Gunawan \\ Universitas Muhammadiyah Sukabumi \\ callmecieee@gmail.com \\ Ike Rachmawati \\ Universitas Padjajaran Bandung \\ ike_rachmawati1@yahoo.com \\ Dine Meigawati \\ STISIP Widyapuri Mandiri \\ dinemeigawati@gmail.com
}

DOI: http://dx.doi.org/10.23969/decision.v1i2.1748

\begin{abstract}
The research is entitled "The Role of Department of Transportation in the Management of Public Transportation in Sukabumi City". The research was aimed at finding out the role of Department of Transportation in managing public transportation. The phenomena identified were unsuitable cost violating the regulations, lack of interest on motor vehicle inspection, service schedule and undistributed public transportation route. The researcher deployed Role theory from Heroepoetri. Dimensions used were role functioning as policy, strategy, means of communication, and mediator. The method applied was qualitative and informants were amounted to seven persons. Data were acquired from observation, interview and observation. Procedure of validation test was conducted by means of source of triangulation, time and technique. The results of the research deploy that the roles of Department of Transportation have not been implemented well due to the in assertiveness towards drivers applying unsuitable cost, avoiding motor vehicle inspection, and "ojeg" than hamper the distribution of public transportation route. In order to make the service of transportation runs maximally, Department of Transportation shall improve their supervision, control, planning, and traffic management regulations.
\end{abstract}

Keywords: Role, Municipal Public Transportation

\begin{abstract}
Abstrak
Judul penelitian ini adalah "Peran Dinas Perhubungan dalam Tata Kelola Angkutan Umum Perkotaan di Kota Sukabumi". Tujuan penelitian ini adalah untuk mengetahui bagaimana peran Dinas Perhubungan Kota Sukabumi dalam menata dan mengelola angkutan umum perkotaan. Fenomena yang peneliti temukan di lapangan adalah tarif yang tidak sesuai dengan peraturan Pemerintah, rendahnya minat uji KIR, jadwal pelayanan dan jalur trayek angkutan umum perkotaan yang belum merata. Peneliti menggunakan teori peran menurut Heroepoetri. Dimensi yang digunakan adalah peran sebagai suatu kebijakan, peran sebagai strategi, peran sebagai alat komunikasi dan peran sebagai alat penyelesaian sengketa. Metode penelitian yang digunakan adalah kualitatif dan informan berjumlah tujuh orang. Data di peroleh melalui observasi, wawancara dan dokumentasi. Prosedur pengujian keabsahan data dilakukan dengan menggunakan
\end{abstract}


triangulasi sumber, waktu dan teknik. Hasil penelitian mengungkapkan bahwa peran Dinas Perhubungan belum berjalan secara maksimal karena belum bertindak tegas kepada pemilik angkutan umum perkotaan yang menetapkan tarif tidak sesuai peraturan, yang tidak melakukan uji KIR dan belum ada tindakan yang tegas terhadap supir ojeg pangkalan yang menghalangi adanya pemerataan akses transportasi. Agar pelayanan transportasi ini dapat berjalan secara maksimal, Dinas Perhubungan Kota Sukabumi perlu meningkatkan lagi pelaksanaan pengawasan, pengendalian, perencanaan dan pengaturan manajemen lalu lintas.

\section{Kata Kunci: Peran, Angkutan Umum Perkotaan}

\section{A. PENDAHULUAN}

Angkutan umum perkotaan adalah salah satu moda transportasi yang sering digunakan oleh masyarakat untuk berpindah dari satu tempat ke tempat lainnya dan masih menjadi primadona di kalangan masyarakat karena harganya yang terjangkau. Berdasarkan SK Walikota Sukabumi No. 70 Tahun 2016, tarif untuk pelajar adalah Rp.2000 dan Rp.3000 untuk umum. Selain itu, angkutan umum perkotaan merupakan bagian dari sistem transportasi yang memegang peranan sangat penting dalam mendukung mobilitas masyarakat sehari-hari. Angkutan umum perkotaan yang tersebar di wilayah Kota Sukabumi ini berjumlah 2092 unit yang terbagi kedalam 20 trayek angkutan umum perkotaan yang tersebar di 7 Kecamatan, yaitu Kecamatan Cikole, Kecamatan Gunung Puyuh, Kecamatan Citamiang, Kecamatan Cibeureum, Kecamatan Baros, Kecamatan Lembursitu dan Kecamatan Warudoyong.

Demi terciptanya angkutan umum yang nyaman, aman dan selamat dilakukan pengujian kendaraan bermotor (KIR) yang dilakukan setiap 6 (enam) bulan sekali. Namun pada kenyataannya masih banyak kendaraan angkutan umum perkotaan yang tidak melakukan pengujian kendaraan bermotor (KIR) yang di sisi lain biaya untuk pengujian kendaraan bermotor (KIR) khusus untuk angkutan umum perkotaan telah di gratisakn oleh
Pemerintah Daerah Kota Sukabumi. Adapun data angkutan umum perkotaan yang melakukan pengujian kendaraan bermotor (KIR) pada tahun 2018 sebagai berikut:

Grafik 1. Data Pengujian Kendaraan Bermotor 2018

GRAFIK : KENDARAAN ANGKUTAN KOTA YANG DI UJI PADA TAHUN : 2018

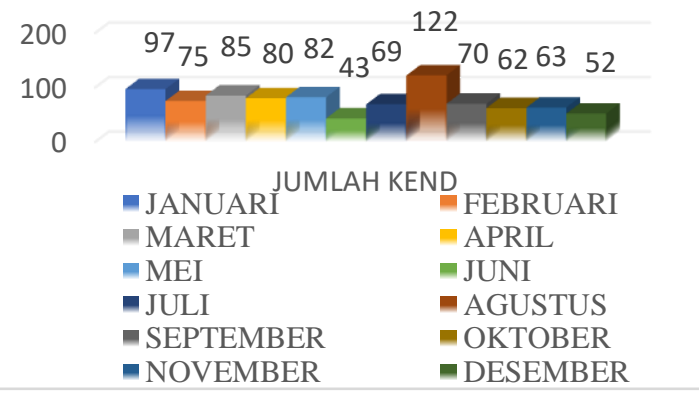

Sumber: Dinas Perhubungan, 2019

Dari grafik diatas dapat di lihat bahwa pengujian kendaraan bermotor (KIR) berjalan sangat tidak stabil. Hal tersebut dibuktikan oleh adanya kenaikan maupun penurunan setiap bulannya dan pengujian kendaraan bermotor (KIR) yang tertinggi terjadi pada bulan Agustus 2018, sebanyak 122 kendaraan melakukan pengujian kendaraan bermotor (KIR) dan yang terendah terjadi pada bulan Juni 2018, sebanyak 43 kendaraan melakukan pengujian kendaraan bermotor (KIR). Penelitian ini bertujuan untuk mengetahui bagaimana peran Dinas 
Perhubungan dalam menata dan mengelola angkutan umum perkotaan di Kota Sukabumi.

\section{B. KAJIAN PUSTAKA}

Peran (role) merupakam aspek dinamis kedudukan (status). Artinya apabila seseorang melaksanakan hak dan kewajibannya sesuai dengan kedudukan, maka orang tersebut menjalankan suatu peran (Narwoko, 2006:158). Peran yang melekat pada diri seseorang harus dibedakan dengan posisi dalam pergaulan kemasyarakatan maupun organisasi. Posisi seseorang dalam masyarakat merupakan unsur statis yang menunjukkan tempat individu pada organisasi masyarakat. Peran lebih banyak menunjukkan pada fungsi, penyesuaian diri, dan sebagai suatu proses. Dengan kata lain, seseorang menduduki suatu posisi dalam masyarakat maupun organisasi serta menjalankan suatu peranan. Masyarakat maupun organisasi biasanya memberikan fasilitas-fasilitas pada individu untuk dapat menjalankan peranan.

Mengenai peran ini, Heroepoetri, Arimbi dan Santosa (dalam Skripsi Anggi Jalaludin: 2017) membagi peran menjadi beberapa dimensi sebagai berikut:

a. Peran sebagai suatu kebijakan

Penganut paham ini berpendapat bahwa peran merupakan suatu kebijakan yang tepat dan baik dilaksanakan.

b. Peran sebagai strategi

Penganut paham ini mendalilkan bahwa peran merupakan strategi untuk mendapatkan dukungan dari masyarakat (public support). Pendapat ini didasarkan pada suatu paham bahwa keputusan dan kepedulian masyarakat pada tiap tingkatan keputusan di dokumentasikan dengan baik, maka keputusan tersebut memiliki kredibilitas.

c. Peran sebagai alat komunikasi

Peran didayagunakan sebagai instrumen atau pengambilan keputusan. Persepsi ini didasarkan oleh suatu pemikiran bahwa pemerintah dirancang untuk melayani rakyat, sehingga pandangan dan preferensi dari masyarakat tersebut adalah masukan yang bernilai guna mewujudkan keputusan secara refrensif.

d. Peran sebagai alat penyelesaian sengketa

Peran didayagunakan sebagai suatu cara untuk mengurangi dan meredam konflik melalui usaha pencapaian konsensus dari pendapat-pendapat yang ada. Asumsi yang melandasi ini adalah bertukar pikiran dan pandangan yang dapat meningkatkan pengertian dan toleransi serta mengurangi rasa ketidak percayaan dan juga kerancuan.

e. Peran sebagai terapi

Menurut persepsi ini, peran dilakukan sebagai upaya mengobati masalah-masalah psikologis masyarakat seperti halnya perasaan ketidakberdayaan, tidak percaya diri dan perasaan bahwa diri mereka bukan komponen penting dalam masyarakat.

Transportasi adalah suatu tindakan, proses, atau hal mentransportasikan atau sedang ditransportasikan dan kata kerja to transport berarti memindahkan dari suatu tempat ke tempat yang lain (Webster's New Collegiate Dictionary dalam Edward K. Morlok). Transportasi juga dapat diartikan sebagai perpindahan orang atau barang dari satu tempat ke tempat lainnya atau dari tempat asal ke tempat tujuan dengan menggunakan sarana yang digerakan 
manusia, hewan atau mesin (Zulfiar Sani dalam Transportasi Suatu Pengantar, 2010:2). Tujuan orang menggunakan alat transportasi adalah agar lebih cepat dan lebih mudah dalam perpindahan orang atau barang dari tempat asal ke tempat tujuannya. Fungsi transportasi ini tidak hanya dilihat secara perorangan tapi juga dilihat dari kepentingan masyarakat luas.

a. Penggerak pembangunan.

b. Penunjang pergerakan barang atau orang dari satu tempat ke tempat yang lain.

Fungsi dari transportasi itu sendiri dapat menggerakan roda ekonomi dari satu daerah yang telah ada karena kegiatan masyarakat di daerah tersebut sudah lebih berkembang dari daerah yang tidak atau belum ada sistem lalu lintas. Dalam kegiatan transportasi tentu banyak faktor pendukung untuk melaksanakan sistem transportasi yang baik. Jika suatu transportasi tidak diatur dengan baik maka bisa jadi menimbulkan berbagai masalah seperti kemacetan dan kecelakaan lalu lintas atau ruang public yang semrawut karena tidak terlaksananya transportasi yang baik. Maka faktor yang mendukung transportasi menjadi lebih baik anatara lain:

a) Rute yang terdiri dari asal, tujuan dan lintasannya.

b) Prasarana (infrastruktur) sesuai dengan transportasi yang digunakan.

c) Sarana alat untuk melakukan perpindahan.

d) Operasional proses pengaturan operasi kendaraan agar dapat seefisien mungkin.

e) Peraturan pelaksanaan yang mengatur penggunaan prasarana oleh sarana karena banyak pemakaian pada saat yang bersamaan pada satu tempat atau ruang. f) Pengawasan agar pemakaian prasarana berjalan tertib sesuai dengan peraturan yang dikeluarkan.

g) Pihak yang menyediakan sarana untuk pelaksanaan perpindahan yang biasanya disebut pengusaha angkutan umum.

h) Penumpang yang memerlukan alat angkut untuk memudahkan perpindahannya dan agar lebih cepat untuk mencapai tujuan yang diinginkan.

Pihak yang terkena dampak angkutan adalah pihak yang terganggu dalam proses pergerakan atau pengoperasian sarana.

\section{METODE PENELITIAN}

Penelitian ini menggunakan pendekatan kualitatif dengan menggunakan grand teori dari Heroepoetri yang memiliki 5 dimensi. Metode penelitian kualitatif ini didefinisikan sebagai metode penelitian ilmu-ilmu sosial yang mengumpulkan dan menganalisis data berupa kata-kata (lisan maupun tulisan) dan perbuatanperbuatan manusia serta peneliti tidak berusaha menghitung atau mengkuantifikasikan data kualitatif yang telah diperoleh dan dengan demikian tidak menganalisis angkaangka (Afrizal, 2014:13).

Untuk menentukan informan dalam penelitian ini, peneliti memilih menggunakan konsep purposive sampling yaitu menentukan subjek/objek sesuai dengan tujuan penelitian. Dengan menggunakan pertimbangan pribadi sesuai dengan topik penelitian, maka peneliti sebagai unit analisis. Peneliti memilih unit analisis tersebut berdasarkan kebutuhannya dan menganggap bahwa unit analisis tersebut representatif (Satori dan Komariah, 2013:47-48). 


\section{HASIL DAN PEMBAHASAN}

Penelitian ini dilaksanakan di Dinas Perhubungan Kota Sukabumi guna mengetahui peran yang dilaksanakan oleh Dinas Perhubungan berkaitan dengan tata kelola angkutan umum perkotaan di Kota Sukabumi. Dengan menggunakan grand teori Heroepoetri yang terdiri dari empat dimensi yaitu:

1. Peran Sebagai Suatu Kebijakan

Kurangnya pengawasan terhadap pelaksana peraturan yang ada oleh Dinas Perhubungan Kota Sukabumi atas ketidaksesuaian tarif yang terjadi di lapangan. Juga belum ada tindakan yang tegas oleh pihak Dinas Perhubungan kepada para supir angkutan umum perkotaan yang menetapkan tarif diluar ketetapan Pemerintah. Dengan begitu, para supir angkutan umum perkotaan menetapkan tarif angkutan umum perkotaan diluar tarif yang telah ditetapkan oleh Pemerintah Kota Sukabumi.

2. Peran Sebagai Strategi

Kurangnya pengaturan, pengawasan dan pengedalian dari Dinas Perhubungan Kota Sukabumi dalam melakukan strategi pengujian kendaraan bermotor (KIR) hal tersebut dapat dilihat dari masih rendahnya minat pengujian kendaraan bermotor (KIR) oleh para pemilik angkutan umum perkotaan dan belum ada sanksi terhadap pemilik angkutan umum perkotaan yang terus menerus membandel. Meskipun Dinas Perhubungan dan Organda sebagai mitra angkutan umum telah memberikan himbauan kepada para pemilik angkutan umum perkotaan untuk selalu melakukan uji KIR apabila sudah waktunya. Tetapi himbauan tersebut seolah-olah diabaikan oleh para pemilik angkutan umum perkotaan.

3. Peran Sebagai Alat Komunikasi

Kurangnya perencanaan penyusunan rencana dan program pelaksanaan implementasinya dan juga kurangnya pengaturan pemetaan sirkulasi lalu lintas oleh pihak Dinas Perhubungan dalam hal ini kaitannya dengan jadwal pelayanan angkutan umum perkotaan. Hal tersebut dapat dilihat bahwa penjadwalan angkutan umum perkotaan ini masih berlaku dan Dinas Perhubungan belum dapat mengeluarkan mengeluarkan kebijakan terbaru perihal penyetaraan jadwal pelayanan angkutan umum karena terhambat oleh persetujuan para ojeg pangkalan.

4. Peran Sebagai Alat Penyelesaian Sengketa

Kurangnya perencanaan dalam hal penetapan pemecahan masalah, penyusunan rencana dan program pelaksanaan implementasinya, kurangnya pengaturan dalam hal pemetaan sirkulasi lalu lintas dan juga kurangnya pengendalian terhadap pemberian arahan dan petunjuk dalam pelaksanaan kebijaksanaan lalu lintas oleh pihak Dinas Perhubungan. Hal tersebut dapat dilihat dari bahwasannya Dinas Perhubungan belum dapat mengarahkan dan membina ojeg pangkalan secara terpadu dan berkala.

\section{E. KESIMPULAN}

Dalam melaksanakan perannya, Dinas Perhubungan Kota Sukabumi mengacu kepada Peraturan Daerah Provinsi Jawa Barat No. 3 Tahun 2011 tentang Penyelenggaraan Perhubungan. Penilaian peran Dinas Perhubungan ini 
peneliti lakukan dengan mengacu pada teori Heroepoetri yaitu:

1. Peran Sebagai Suatu Kebijakan, peran Dinas Perhubungan Kota Sukabumi belum dapat berjalan secara maksimal. Karena dalam pelaksanaan suatu kebijakan terutama perihal tarif angkutan umum perkotaan masih belum sesuai dengan apa yang telah ditetapkan oleh pemerintah.

2. Peran Sebagai Strategi, peran Dinas Perhubungan dalam meningkatkan pengujian kendaraan bermotor (KIR) belum sepenuhnya berjalan sesuai dengan apa yang seharusnya. Hal tersebut dibuktikan dengan masih rendahnya minat pemilik angkutan umum perkotaan untuk melakukan pengujian kendaraan mereka secara berkala dan belum adanya sanksi kepada pemilik angkutan umum perkotaan yang tidak melakukan pengujian kendaraan bermotor.

3. Peran Sebagai Alat Komunikasi, meskipun Dinas Perhubungan telah melakukan komunikasi dengan pihak-pihak yang bersangkutan terkait pemerataan jadwal, tetapi Dinas Perhubungan belum dapat bertindak tegas terhadap para supir ojeg pangkalan yang membandel. Sehingga pemerataan jadwal belum dapat terlaksanakan dengan baik seperti apa yang seharusnya.

Peran Sebagai Alat Penyelesaian Sengketa, rencana Dinas Perhubungan tersebut terhambat oleh kesepakatan ojeg pangkalan yang tidak terima adanya angkutan umum perkotaan yang melintasi wilayah mereka. Dapat peneliti simpulkan bahwa dalam menyelesaikan sengketa, dalam hal ini pembukaan jalur trayek baru Dinas Perhubungan belum dapat melaksanakan perannya dengan baik.

\section{Daftar Pustaka}

Adisasmita, Rahardjo 2015. Analisis Kebutuhan Transportasi. Yogyakarta: Graha Ilmu.

Afrizal. 2014. Metode Penelitian Kualitatif. Jakarta: PT RajaGrafindo Persada.

Ahmad, Jamaludin. 2015. Metode Penelitian Administrasi Publik Teori dan Aplikasi. Yogyakarta: Gava Media.

Bungin, Burhan. 2007. Penelitian Kualitatif. Jakarta: Kencana Pernada Media.

Gibson, James. P. Ivancevich. dkk. 2006. Organisasi dan Manajemen. Jakarta: Erlangga.

K. Morlok, Edward. Pengantar Teknik dan Perencanaan Transportasi. Jakarta: Penerbit Erlangga.

Narwoko, Dwi. 2006. Sosiologi Teks Pengantar dan Terapan. Jakarta: Kencana.

Noor, Juliansyah. 2017. Metodologi Penelitian. Jakarta: Kencana.

Rachmawati, Ike. dkk. 2018. Pedoman Penulisan Ristik dan Skripsi. Sukabumi:

Sadyohutomo, Mulyono. 2009. Manajemen Kota dan Wilayah. PT. Bumi Aksara: Jakarta.

Satori, Djam'an dan Aan Komariah. 2013. Metodologi Penelitian Kualitatif. Bandung: CV Alfabeta.

Sani, Zulfiar. 2010. Transportasi Suatu Pengantar. Jakarta: Universitas Indonesia-Press.

Setijowarno, D dan Frazila. 2001. Pengantar Sistem Transportasi. Semarang: Universitas Katolik Soegijapranata.

Sugiyono. 2008. Metode Penelitian Administrasi. Bandung: Alfabeta.

Sugiyono. 2018. Metode Penelitian Kuantitatif, Kualitatif, dan $R \& D$. Bandung: Alfabeta.

Warpani, $\quad$ Suwardjoko. 2002. Pengelolaan Lalu Lintas dan 
Angkutan Jalan. Bandung: Penerbit ITB.

\section{Artikel KTI/Jurnal:}

Dewi Purita, Eva. 2013. Pengelolaan Transportasi Umum di Jalan Malioboro Yogyakarta. Yogyakarta: Skripsi Program Studi Ilmu Administrasi Negara. FISIP Universitas Negeri Yogyakarta.

Miharti, Pranita. 2018. Koordinasi Dinas Perhubungan dalam Meningkatkan Pelayanan Jasa Transportasi Angkutan Kota (ANGKOT) di Bandar Lampung. Bandar Lampung: Skripsi Program Studi Administrasi Negara. FISIP Universitas Lampung.

Jalaludin, Anggi. 2017. Peran Dinas Kebudayaan Kepemudaan dan Olahraga dalam Meningkatkan Prestasi Atlet di Kabupaten Sukabumi. Sukabumi: Skripsi Program Studi Ilmu Administrasi Publik.

\section{Aturan dan Undang-Undang:}

- Peraturan Daerah Provinsi Jawa Barat Nomor 3 Tahun 2011 tentang Penyelenggaraan Perhubungan.

- Peraturan Walikota Sukabumi Nomor 2 Tahun 2018 tentang Tarif Retribusi Izin Trayek

- Surat Keputusan Walikota Sukabumi No. 70 Tahun 2016 tentang Tarif Angkutan Kota Dalam Wilayah Kota Sukabumi 